\title{
OPORTUNIDADES Y DESAFÍOS DEL SECTOR DE PRODUCTOS NATURALES EN COLOMBIA. UNA MIRADA DESDE LA BIOECONOMÍA
}

\section{OPPORTUNITIES AND CHALLENGES OF THE NATURAL PRODUCTS SECTOR IN COLOMBIA. A LOOK FROM THE BIOECONOMY}

Autor 1. Olga Lilihet Matallana Kuan

Economista, Especialista en gerencia de Recurso Humano Magister en

Administración, UNAD, Líder semillero de investigación Ideas en Acción

Correo electrónico: olga.matallana@unad.edu.co

ORCID: 0000-0002-3563-1668

Autor 2. Mary Luz Benavides Bolaños

Estudiante Administración de Empresas, UNAD, Semillero de investigación Correo electrónico: malubenavidesb@gmail

Autor 3. Adriana Valentina Sánchez Rodríguez

Estudiante Administración de Empresas, UNAD, Semillero de investigación

Correo electrónico: adrianavalentinasanchez1702@gmail.com

Autor 4. Sandra Milena González

Estudiante Administración de Empresas, UNAD, Semillero de investigación

Correo electrónico: sandraabrilgo@hotmail.com

\section{RESUMEN}

El sector de productos naturales de uso medicinal, cosmético y nutritivo, ha despertado gran interés en los consumidores por considerarse una alternativa menos agresiva que los medicamentos químicos, pues se basan en plantas medicinales y se orientan a salud, bienestar y alimentación; En Colombia, el tema puede tener un elevado potencial de desarrollo por la enorme biodiversidad y las dinámicas crecientes del mercado mundial en este tipo de sustancias. El sector, cuenta con innumerables retos como la incertidumbre respecto al marco legal para la producción y uso de estos productos, mayor desarrollo científico e investigativo en torno a las propiedades de las plantas y la ausencia de políticas de estado para fomentar suficientemente los procesos investigativos en bioeconomía, ademas, muchos productos y tiendas informales no cuentan con los requisitos exigidos y pueden constituirse en un riesgo para la salud pública, para el estudio planteamos la siguiente pregunta de investigación:¿Conocer el estado actual de sector de productos naturales, mediante la metodología de diseño sectorial permitirá establecer adecuadamente las condiciones favorables, desfavorables y de desarrollo del mismo?

El objetivo es determinar las oportunidades y desafíos del sector de productos naturales en el país; incluyendo la revisión de avances del sector en bioeconomía, a través de un estudio 

Para La Organización de las Naciones Unidas para la educación, la ciencia y la cultura (UNESCO), existen varias técnicas para realizar análisis sectoriales (...) donde se destacan: la Evaluación del impacto que consiste en examinar la importancia económica directa del sector concernido, en términos de contribución a la producción, al ingreso y al empleo (...). El Análisis de la estructura sectorial, referido a la evaluación de los agregados macroeconómicos tales como la producción, el consumo de los hogares, las exportaciones o la demanda total. (...).

Da la posibilidad de identificar tanto las fortalezas como los cuellos de botella de la cadena productiva de un subsector y conocer su grado de competitividad. (Unesco, 2014). En ese orden de ideas se plantea de manera preliminar las variables a abordar en el marco de la técnica PESTEL que permite analizar el macroentorno y determinar oportunidades $y$ amenazas del sector basadas en las variables de análisis descritas en la tabla 1.

Tabla 1

\begin{tabular}{|c|c|c|}
\hline $\begin{array}{l}\text { Variables } \\
\text { análisis }\end{array}$ & $\begin{array}{l}\text { d } \begin{array}{l}\text { Dimensiones } \\
\text { subcategorías }\end{array}\end{array}$ & Aspectos a indagar \\
\hline N/A & Aspectos generales & $\begin{array}{l}\text { Antecedentes del sector, caracterización del } \\
\text { sector en el País, importancia del sector }\end{array}$ \\
\hline Político & Políticas publicas & Reglamentaciones \\
\hline \multirow[t]{3}{*}{ Económico } & Mercado nacional & $\begin{array}{l}\text { Nuevos competidores, Proveedores, fijación y } \\
\text { control de precios, Empresas, tendencias futuras } \\
\text { del mercado. }\end{array}$ \\
\hline & Cadena de valor & $\begin{array}{l}\text { Producción [laboratorios de productos Naturales } \\
\text { Distribución [Tiendas naturistas, Droguerías, } \\
\text { Centros médicos, Médicos independientes, } \\
\text { Grandes Superficies, Catálogos], Consumo }\end{array}$ \\
\hline & $\begin{array}{l}\text { Factores } \\
\text { macroeconómicos }\end{array}$ & $\begin{array}{l}\text { Importaciones, Exportaciones, Mercados } \\
\text { internacionales }\end{array}$ \\
\hline Socio Cultural & Capital Humano & $\begin{array}{l}\text { Empleo, educación superior en áreas de impacto } \\
\text { en el sector, salarios, personal cualificado }\end{array}$ \\
\hline \multirow[t]{2}{*}{$\begin{array}{l}\text { Tecnológico y } \\
\text { ambiental }\end{array}$} & $\begin{array}{l}\text { Investigación+ desarroll } \\
\text { e innovación }\end{array}$ & $\begin{array}{l}\text { Investigación de Fitoterapéuticos, Desarrollo de } \\
\text { bioeconomía, Grupos de investigación, } \\
\text { Oportunidades de innovación en el sector. }\end{array}$ \\
\hline & Medio ambiente & Manejo de productos residuales \\
\hline Legal & $\begin{array}{l}\text { Normatividad y entidade } \\
\text { regulatorias }\end{array}$ & $\begin{array}{l}\text { Marco regulatorio INVIMA, Ministerio de Salud, } \\
\text { Ministerio de Agricultura, agremiaciones, } \\
\text { Superintendencia de Industria y Comercio. }\end{array}$ \\
\hline
\end{tabular}

Fuente: elaboración propia basado en análisis documental

\section{DISCUSIÓN Y RESULTADOS PARCIALES}

La industria naturista en Colombia está compuesta de los cultivadores de plantas, Distribuidores y comercializadores de plantas aromáticas y medicinales, laboratorios de productos Fitoterapéuticos, Homeopáticos, Cosméticos y de alimentos, comercializadores e importadores de productos Naturales, las tiendas naturistas y farmacias homeopáticas, la industria naturista colombiana genera 50.000 empleos directos y cuenta con 9.000 tiendas, 250 distribuidores autorizados y 37 laboratorios en todo el país. Sus ventas anuales se estiman en $\$ 3.000$ millones, ademas de contribuir en impuestos con $\$ 16.000$ millones entre 



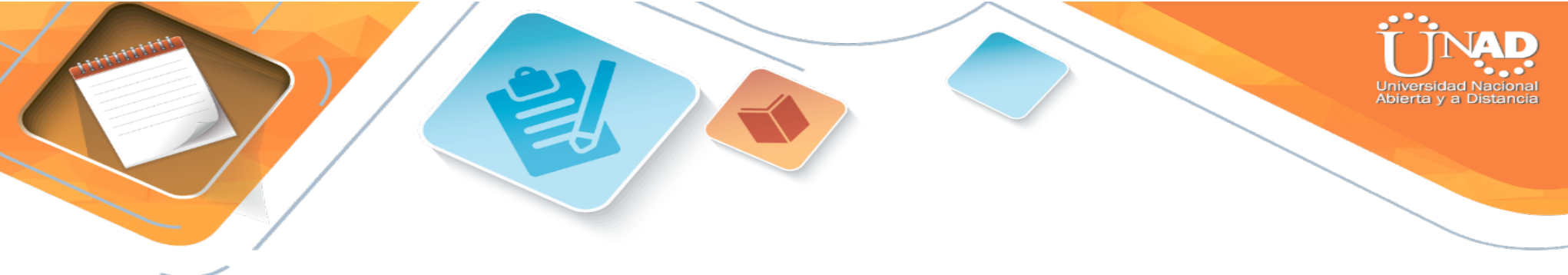

Asonatura. (2013). Anuario de la industria naturista, 6. Recuperado de https://issuu.com/anuarioasonatura/docs/anuario_asonatura_2103

Buitrago, G. (2012). Tres décadas de biotecnología en Colombia. Revista Colombiana de Biotecnología, 14(2), 5-6. Recuperado de http://www.scielo.org.co/pdf/biote/v14n2/v14n2a01.pdf

Guevara, H. Luengas, P. y Garavito, G. (2010). Revisión documental de los productos naturales legalmente autorizados para su mercadeo en Colombia. Colombia Médica, 41(2), 129-140. Recuperado

http://www.scielo.org.co/scielo.php?script=sci_arttext\&pid=S1657-

95342010000200004\&Ing=en\&tIng=es.

Instituto Español de Comercio Exterior. (2005). El sector de Productos Naturales en Colombia. Recuperado de https://sioc.minagricultura.gov.co/PlantasAromaticas/Documentos/004\%20\%20Documentos\%20Competitividad\%20Cadena/D.C. \%20\%E2\%80\%93\%202005\%20F ebrero\%20\%E2\%80\%93\%20Bogota\%20\%E2\%80\%93\%20Notas\%20Sectoriales.pdf

INVIMA. Decreto 2266 de 2004. (2004). Recuperado de https://www.invima.gov.co/decretosen-productos-fitoterapeuticos/decreto-2266-2004-pdf/detail.html

Rúgeles Chacón, L. E., Ortiz, J., Díaz, G., Bladimir, L., \& Huertas, D. A. (2012). La cadena de valor de los ingredientes naturales del Biocomercio para las industrias farmacéutica, alimentaria y cosmética-FAC. Universidad de Bogotá 